\section{SPONTANEOUS RUPTURE OF THE URINARY BLADDER}

\author{
WITH THE REPORT OF A CASE \\ BY
}

WILLIAM MORTON, M.B., CH.B.

ASSISTANT MEDICAL OFFICER, ANLABY ROAD HOSPITAL, HULL

It is customary to classify ruptures of the urinary bladder as extraperitoneal and intraperitoneal, and as traumatic and spontaneous. I report this case of spontaneous intraperitoneal rupture of the bladder in the hope that it may be of interest because of the rarity of the condition and the unusual contributory cause.

\section{Case History}

The patient, a female aged 37, single, and a domestic servant, first consulted her doctor complaining of painful and difficult micturition. Cystitis was present, and the usual alkaline diuretic mixture was prescribed. Three days later she sent for the doctor. He found a large tumour, resembling in appearance a nine-months pregnancy, arising from the pelvis, and on examination per vaginam made a diagnosis of uterine fibroids. He advised her immediate admission to hospital, but unfortunately she refused to follow this advice.

The following day he received an urgent summons to the patient. She was in a state af collapse, cyanosed, and practically pulseless, and had vomited frequently during the day. Her relatives said that she had become steadily worse during the past twenty-four hours, and in that time had passed very little urine, but she would not allow them to send for the doctor. She had begun to menstruate three days previously.

I give the doctor's own description of his findings. "The abdomen was distended and tympanitic. It looked like a fulltime pregnancy. On examination per vaginam $I$ found the vaginal mucous membrane very swollen and turgid. There was menstrual discharge. Posteriorly a large fibroid was felt. I had been given a history of difficult micturition, but total retention had only been present for twelve hours. Accordingly I passed a catheter and withdrew twelve ounces of urine, which contained blood and pus. The meatus was' difficult to find on account of the swollen mucosa and the menstrual discharge, but once inserted the catheter passed quite easily into the bladder."

Thereupon he sent the patient to hospital, where I saw her. On admission she obviously was in extremis, and too ill either for examination or for surgical intervention. She died within fifteen minutes of admission. Permission for a postmortem examination was granted.

\section{Post-mortem Findings}

On opening the abdomen I found a condition of generalized peritonitis. There was a quantity of fluid in the right side below the liver, and extending down to the dome of a large globular tumour, which arose from the pelvis. This collection of fluid was shut off by omentum. The tumour was found to be a greatly distended urinary bladder. From the apex of the distended fundus a stream of urine was escaping from a small perforation, situated slightly to the left of the mid-line. The body of the uterus carried three large mural fibroids, and a fourth from the posterior surface of the cervix was wedging itself and the uterus into the pelvic cavity. The left kidney pelvis was slightly dilated. Nothing of note was found in the other abdominal, pelvic, or thoracic organs. The apex of the distended bladder was stretched and thinned to such an extent that it was almost transparent. The mucous membrane was inflamed, and over an area of one square inch was necrotic. In the centre of this necrotic area was the perforation already described. The mucosa of the whole bladder was oedematous and inflamed. Urine obtained post mortem contained blood, pus, $B$. coli, and various cocci.

\section{Discussion}

Retention of urine must have resulted from the presence of the uterine fibromyomata. It could have been caused either by direct pressure of the fibroids or by the growing tumour displacing the bladder upwards and forwards, thus stretching and distorting the urethra. In this case both factors were probably present, for pressure of fibroids on the neck of the bladder would produce oedema, and so partially obstruct the urinary outflow. The patient's doctor stated that he had no difficulty in passing the catheter into the bladder once it was inserted, so the mechanical pressure cannot have created a complete stoppage of the urethra. Further, he stated he had difficulty in finding the meatus, which difficulty would be explained by a stretched urethra pulling its orifice within the vagina. Also the fact that menstruation had begun three days before rupture occurred suggests that the increased pelvic congestion so produced changed a partial into a complete retention. Retention of urine is a well-known complication of a retrodisplaced pregnant uterus, and it is of interest to note that in such cases actual rupture has taken place. ${ }^{1}$

In the absence of other sources of infection the cystitis must have been subsequent to the retention. The oedema around the bladder neck would interfere with the blood supply to the whole organ. These two conditions-infection and circulatory impairment-would lead to necrosis, and eventually, with further distension, necrosis would be followed by perforation. The escaping urine had been walled off to form what might be described as a farextending subphrenic collection of fluid. H. W. Cave ${ }^{2}$ has reported a case of spontaneous rupture of the bladder in an elderly woman, in which the condition found on operation was similar to that found in this case. $\mathrm{He}$ writes:

" From the upper quadrant two gallons of clear flu:d were evacuated; the greater omentum had for some unexplained reason walled off this large quantity of fluid beneath the liver. ... We found, to our surprise and delight, a small punched-out hole in the dome of the bladder, to the left of the mid-line. From the opening fluid trickled."

Spontaneous rupture of the bladder fortunately is of rare occurrence. In a series of twenty-two cases of rupture reported by Kahle and Beacham ${ }^{3}$ four were classified as spontaneous. In these four a pathological condition of the bladder wall was found, and in three obstruction had been caused by a hypertrophied prostate. B. H. Alton ${ }^{4}$ described another case, which occurred in a patient with a tuberculous bladder. A. T. Jones ${ }^{5}$ reports a case in which rupture was produced in a woman with a distended bladder by the very gentle exertion of sitting up in bed to swallow some medicine; but probably this should be classified as traumatic.

From the foregoing it would appear that spontaneous rupture of the bladder does occur, and that the two precursors of this event are distension and a pathological condition of the bladder walls. How long these two conditions had been present in the case $I$ have described it is impossible to tell. A patient so reticent as this one would have suffered pain and discomfort for many months without seeking advice. From the history, retention must have existed for some considerable time, and apparently had been subject to remissions. In brief, the pathological sequence would appear to have been: uterine fibroids, partial retention of urine, cystitis, onset of menstruation, perforation, and, finally, fatal peritonitis.

I wish to express my thanks to Dr. N. Gebbie, medical officer of health, for permission to publish this report; to Dr. D. L. Macrae Tod, senior medical officer, for helpful sugges. tions ; and to Drs. Barker and Dunn for the information they kindly gave me about the early history of the case.

\section{REFERENCES}

${ }^{1}$ Munro Kerr, Ferguson, Young, Hendry: A Combined Textboo of Obstetrics and Gynaecology.

${ }^{2}$ Cave, H. W.: Amer. Journ. Surg., May, 1935

${ }^{3}$ Kahle, P. J., and Beacham, H. T.: Urological and Cutaneous Review, June, 1935.

Alton, B. H.: New England Journ. Med., December, 1931

Jones, A. T.: Ibid., June, 1934. 